\title{
Visceral abdominal fat measured by computer tomography as a prognostic factor for gynecological malignancies?
}

\author{
Johanna Nattenmüller ${ }^{1, *}$, Joachim Rom ${ }^{2, *}$, Tom Buckner ${ }^{3}$, Jalal Arvin ${ }^{2}$, Benedikt \\ Bau $^{2,5}$, Christof Sohn ${ }^{2}$, Hans-Ulrich Kauczor ${ }^{1}$ and Sarah Schott ${ }^{2,4}$ \\ ${ }^{1}$ Department of Diagnostic and Interventional Radiology, University Hospital, Heidelberg, Germany \\ ${ }^{2}$ Department of Obstetrics and Gynecology, University Hospital, Heidelberg, Germany \\ ${ }^{3}$ Department of Medical Biometry and Informatics, University Heidelberg, Heidelberg, Germany \\ ${ }^{4}$ NCT Heidelberg, DKTK Heidelberg, Heidelberg, Germany \\ ${ }^{5}$ Department of Gynecology and Obstetrics, Regional Hospital Nordjylland, Hjørring, Denmark \\ *These authors have contributed equally to this work and defined as co-first author \\ Correspondence to: Johanna Nattenmüller, email: johanna.nattenmueller@med.uni-heidelberg.de \\ Keywords: body composition; BMl; obesity; gynecological malignancies; computed tomography \\ Received: December 19, $2017 \quad$ Accepted: February 27, $2018 \quad$ Published: March 27, 2018 \\ Copyright: Nattenmüller et al. This is an open-access article distributed under the terms of the Creative Commons Attribution \\ License 3.0 (CC BY 3.0), which permits unrestricted use, distribution, and reproduction in any medium, provided the original author \\ and source are credited.
}

\section{ABSTRACT}

Introduction: Obesity is associated with increased incidence of ovarian (OC), cervical (CC) and endometrium cancer (EC). However, the impact of body composition (BC) on overall survival (OS), especially of visceral adipose tissue (VAT) is not yet understood.

Methods: In 189 women with gynecological malignancies (31 OC, 104 CC, 54 EC, mean age 62.9y; mean BMI $26.8 \mathrm{~kg} / \mathrm{m}^{2}$; median follow-up 30.7 months) with routine staging CT-scans at baseline (mean interval: 4.3 months), densitometric quantification of total (TAT), visceral, and subcutaneous-fat-area (SAT), inter-muscular-fat-area (IMFA), and skeletal-muscle-index (SMI) was performed to analyze the impact of BC on survival.

Results: With a mean follow-up of $\mathbf{3 0 . 7}$ months 48 patients had died. We observed no significant differences regarding BMI, the adipose- and muscle-distribution between surviving and deceased women. Univariate analyses revealed no significant BC-parameter with impact on OS, which was confirmed by different multivariate models. A subgroup analysis of $\mathrm{OC}, \mathrm{CC}$ and EC showed only a protective impact of SMI on survival in the subgroup of $\mathrm{CC}$.

Conclusions: Despite the increased incidence of gynecological malignancies in obese, we found no significant impact of BC including VAT on patient survival. Further studies with larger cohorts are needed to quantify BC and its metabolomic impact regarding treatment and prognosis.

\section{INTRODUCTION}

Overweight and obesity represent a major global health challenge in the 21 st century [1]. Half of the population of high-income countries by now is overweight or obese [2]. Worldwide, the incidence has nearly doubled to $12 \%$ in adults in 2015 [1]. Obesity is a complex chronic disease with impaired quality of life, high morbidity and mortality, and is an important factor for overall global mortality [1,3]. In $2015,7.1 \%$ of deaths of any cause were related to high BMI with rising death rates. Overweight and obesity have some of the fastest rising incidences among health risks [1]. Obesity is especially associated with an increased mortality from cardiovascular disease and diabetes, but also from various cancers $[1,2,4-11]$. Yet, the underlying pathophysiology and mechanism 
to most diseases is not fully understood. Therefore, it is important to develop new therapeutic and prophylactic strategies against obesity to limit health care complications as well as public expenses $[1,12]$.

Obesity is a risk factor for intra- as well as postoperative complications and remains a considerable, relative contraindication to complex surgical procedures especially in oncological situations $[13,14]$. Furthermore, adiposity triggers several comorbidities and limits the use and success of chemotherapeutic and immunological drug regimens [15-17]. The baseline level of inflammation varies in obese and can limit new immunotherapeutic strategies not only due to different responses, but also due to elevated side effects [18].

Obesity is associated with $9 \%$ of cancers in female patients [19]. The risk of developing endometrial cancer (EC) has been described as proportional to the second power of the body mass index (BMI) [20]. A metaanalysis including 19 prospective studies showed a strong association between a $5 \mathrm{~kg} / \mathrm{m}^{2}$ increase in BMI and EC [21]. Every 5 BMI units increase the EC-risk by $50 \%$, and even within the normal BMI range an elevated risk is apparent [22]. Obesity is also associated with an increased risk for all-cause mortality in EC, with the risk being highest for class III obesity (BMI $\geq 40$ ) [23]. Similarly, the incidence of ovarian cancer (OC) and mortality of OC and cervix cancer (CC) is increased in obese [9, 24].

So far, BMI, waist circumference or waist-to-hip ratio at the time of diagnosis have been correlated with prognosis and outcome in gynecological malignancies $[25,26]$. But BMI is not able to differentiate between an elevation of fat or muscle tissue. Recently, it has been shown that beyond BMI local fat deposits, especially visceral abdominal fat tissue (VAT), are associated with an increased risk of colon carcinoma $[10,27]$. Also, visceral obesity is associated with poor outcome in colorectal cancer patients [28, 29]. Additionally, it is known that tissue composition changes the metabolic, hormonal and digestive properties of a body and might impact drug treatment and cancer metabolome [30].

This study was designed to evaluate the prognostic significance of high VAT in patients with gynecological malignancies. According to our knowledge, this is the first study that examines the exact body composition in these patients.

\section{RESULTS}

In total 189 women were included in this study. Detailed characteristics of the whole study population, including cancer entities and stages, are provided in Table 1. In brief, the average participant was aged 62.9 years, overweighed with an average BMI of 26.8, had given birth (64\%) and had no exposure to a hormontherapy in the past $(44.4 \%)$. Most women underwent chemotherapy $(78.3 \%)$ as well as radiotherapy $(78.8 \%)$.
Most participants suffered from a cervical cancer (55.0\%) followed by endometrium $(28.6 \%)$ and ovarian cancer (16.4\%). Endometrium cancer patients had the highest BMI with (28.4) followed by ovarian cancer patients (26.3), the lowest BMI was found among the cervical cancer patients (26.1). The Rx was classified either if an inoperable situs of an ovarian cancer was detected or if a definite radiochemotherapy was performed.

The median follow-up time for the last data analysis was 30.7 months (range 7-72 months). At the time point of last data analysis 141 patients $(74.2 \%)$ were still alive, 48 patients $(25.3 \%)$ had died.

In the total patient group $34.8 \%$ of patients had sarcopenia, and $65.2 \%$ of patients did not.

In the cervix cancer patient group $34.2 \%$ of patients had sarcopenia, and $65.9 \%$ of patients did not.

In the ovarian cancer patient group $32.0 \%$ of patients had sarcopenia, and $68.0 \%$ of patients did not.

In the endometrial cancer patient group $37.3 \%$ of patients had sarcopenia, and $62.8 \%$ of patients did not.

\section{Distribution of adipose and muscle tissue}

Mean values and their standard deviations of TAT, VAT, SAT and VAT/SAT as well as SMI and IMFA quantified at the L3/4 spinal level, are given in Table 2. The mean TAT L3/4 $\left(\mathrm{cm}^{2}\right)$ was $385.2 \pm 27.4 \mathrm{~cm}^{2}$. In an agedependent analysis with respect to the median age of 63 years there was only a slight but insignificant difference noticed.

The mean VAT L3/4 $\left(\mathrm{cm}^{2}\right)$ was $117.3 \pm 26.6$ and also the age-dependent analysis did not reveal any significant differences. Same results were detected for the SAT L3/4 $\left(\mathrm{cm}^{2}\right)$ and SMI L3/4 $\left(\mathrm{cm}^{2}\right)$ with a mean of 298.5 \pm 82.6 and $43.1 \pm 24.3$, respectively.

\section{Comparison of surviving vs. deceased patients}

In order to analyze the impact of body composition on survival we subgrouped the study population between women still alive versus those who had died. The Satterthwaite t-test performed in order to analyze differences between surviving and deceased patients (total group of all cancer entities) showed no statistical significant differences between the both groups regarding BMI (27.1 vs. 25.9), TAT (399.5 vs. 341.8), VAT (117.6 vs. 115.7), SAT (302.8 vs. 285.1), VAT/SAT (0.47 vs. $0.56)$, IMFA (37.6 vs. 36.2 ) as well as SMI (43.6 vs. 41.3 ). Details are provided in Table 3.

\section{Survival analysis}

The Kaplan-Meier analyses revealed no significant differences between the OC, CC and EC subgroup. Differences on the follow up period were recognized with a median follow-up of 30.7 (range 8-77 months). CC was the lowest among the subgroups (Figure 1). 
Table 1: Subject characteristics, tumor side and FIGO classification of patients, $\mathbf{n}=189$. Brackets indicate $\%$

\section{General Study Population}

Total number of patients

Age, year (mean $\pm \mathrm{SD})$

$\operatorname{BMI}\left(\mathrm{kg} / \mathrm{m}^{2}\right)$

Nulliparity

Yes

No

Unknown

Hormontherapy in anamnesis

Yes

No

Unknown

Chemotherapy

Yes

No

Radiotherapy

Yes

No

Radiochemotherapy

Yes

No

Endometrium

BMI $\left(\mathrm{kg} / \mathrm{m}^{2}\right)$ Mean \pm SD

FIGO stadium

FIGO $<$ IIIC

FIGO $\geq$ IIIC

unknown

Nulliparity

Yes

No

Unknown

Hormontherapy in anamnesis

Yes

No

Unknown

Chemotherapy

Yes

No
$189(100.0)$

$62.88 \pm 13.53$

$26.81 \pm 6.31$

$28(14.8)$

$121(64.0)$

$40(21.2)$

$25(13.2)$

84 (44.4)

$80(42.3)$

$148(78.3)$

41 (21.7)

149 (78.8)

40 (21.2)

$100(52.9)$

89 (47.1)

$28.37 \pm 7.49$

$41(21.7)$

$12(6.3)$

$1(0.5)$

$10(18.5)$

35 (64.8)

9 (16.7)

7 (13.0)

22 (40.7)

25 (46.3)

$25(46.3)$

$29(53.7)$

(Continued) 


\begin{tabular}{lc}
\hline Endometrium & $\mathbf{5 4}(\mathbf{2 8 . 6 )}$ \\
\hline Radiotherapy & \\
Yes & $48(88.9)$ \\
No & $6(11.1)$ \\
Radiochemotherapy & \\
Yes & $11(20.4)$ \\
No & $43(79.6)$ \\
\hline
\end{tabular}

\begin{tabular}{lc}
\hline Ovarian cancer & $\mathbf{3 1}(\mathbf{1 6 . 4 )}$ \\
\hline BMI $\left(\mathrm{kg} / \mathrm{m}^{2}\right)$ Mean \pm SD & $26.34 \pm 4.40$ \\
FIGO stadium & \\
FIGO $<$ IIIC & $14(7.4)$ \\
FIGO $\geq$ IIIC & $15(7.9)$ \\
unknown & $2(1.1)$ \\
Nulliparity & \\
Yes & $1(3.2)$ \\
No & $20(64.5)$ \\
Unknown & $10(32.3)$ \\
Hormontherapy in anamnesis & \\
Yes & $5(16.1)$ \\
No & $13(41.9)$ \\
Unknown & $13(41.9)$ \\
Chemotherapy & \\
Yes & $30(96.8)$ \\
No & $1(3.2)$ \\
Radiotherapy & \\
Yes & $5(16.1)$ \\
No & $26(83.9)$ \\
Radiochemotherapy & \\
Yes & \\
No & $26(83.9)$ \\
\hline
\end{tabular}

\begin{tabular}{lc}
\hline Cervical cancer & $\mathbf{1 0 4} \mathbf{( 5 5 . 0 )}$ \\
\hline BMI $\left(\mathrm{kg} / \mathrm{m}^{2}\right)$ Mean \pm SD & $26.13 \pm 6.04$ \\
FIGO stadium & \\
FIGO $<$ III & $49(25.9)$ \\
FIGO $>$ III & $55(29.1)$
\end{tabular}

(Continued) 


\begin{tabular}{lc}
\hline Cervical cancer & $\mathbf{1 0 4} \mathbf{( 5 5 . 0 )}$ \\
\hline Nulliparity & $17(16.3)$ \\
Yes & $66(63.5)$ \\
No & $21(20.2)$ \\
Unknown & \\
Hormontherapy in anamnesis & $13(12.5)$ \\
Yes & $49(47.1)$ \\
No & $42(40.4)$ \\
Unknown & \\
Chemotherapy & $93(89.4)$ \\
Yes & $11(10.6)$ \\
No & \\
Radiotherapy & $96(92.3)$ \\
Yes & $8(7.7)$ \\
No & \\
Radiochemotherapy & $84(80.8)$ \\
Yes & $20(19.2)$ \\
No & \\
\hline
\end{tabular}

Table 2: Total and age stratified distribution (area in $\mathrm{cm}^{2}$ ) of adipose tissue compartments (TAT, VAT, SAT) and SMI at level of lumbal vertebra $L 3 / 4, n=189$

\begin{tabular}{lccc}
\hline Variable & Mean \pm SD & Age $<$ median & Age $>$ median \\
\hline TAT L3/4 $\left(\mathbf{c m}^{2}\right)$ & $385.23 \pm 27.4$ & $389.3 \pm 27.4$ & $381.3 \pm 27.4$ \\
VAT L3/4 $\left(\mathbf{c m}^{2}\right)$ & $117.3 \pm 26.6$ & $122.8 \pm 24.89$ & $111.89 \pm 28.6$ \\
SAT L3/4 $\left(\mathbf{c m}^{\mathbf{2}}\right)$ & $298.5 \pm 82.6$ & $311.13 \pm 88.4$ & $288.42 \pm 69.5$ \\
SMI L3/4 $\left(\mathbf{c m}^{\mathbf{2}}\right)$ & $43.1 \pm 24.3$ & $42.96 \pm 27.3$ & $43.2 \pm 16.9$ \\
IMFA & $37.6 \pm 18.7$ & \pm & \pm \\
\hline
\end{tabular}

$\mathrm{SD}=$ standard deviation, $\mathrm{TAT}=$ total adipose tissue, $\mathrm{VAT}=$ visceral adipose tissue, $\mathrm{SAT}=$ subcutaneous adipose tissue, SMI-skeletal-muscle-index, IMFA= inter-muscular-fat-area.

\section{Survival and body composition}

The univariate Cox regressions were performed to analyze the prognostic impact of the specific body composition on survival. BMI $(\mathrm{p}=0.3774)$, TAT $(\mathrm{p}=$ $0.1912)$, VAT $(\mathrm{p}=0.9164)$, SAT $(\mathrm{p}=0.7513)$, VAT/SAT $(\mathrm{p}=0.1167)$, as well as IMFA $(\mathrm{p}=0.9366)$ showed no significant impact on OS in the total study population (see Table 4). SMI has a trend to impact survival with a p-value of $p=0.0717$, but yet not significant.

Also, multivariate analysis performed with various models (formed empirically as well as by forward selection) revealed no significant impact of these parameters on patient's survival (Supplementary Table 1).

\section{Subgroup analysis of cancer type}

Only in the CC subgroup a high amount of muscle tissue (SMI) was associated with a better survival $(\mathrm{p}=0.0226, \mathrm{HR}=0.959) \quad$ (Table 4). The univariate Cox regressions of BMI, TFA, VFA, SFA, VFA/SFA, IMFA as well as SMI showed no significant impact on overall survival in the subgroup of OC, EC and CC (excepting SMI), respectively (Supplementary Table 2).

\section{DISCUSSION}

This retrospective study investigated the impact of body composition beyond BMI on the overall survival in women with OC, CC and EC. To this end we conducted 
Table 3: T-test of surviving $(n=142)$ vs. deceased patients $(n=46)$

\begin{tabular}{lccc}
\hline Variable & Alive mean + SD & Deceased mean+ SD & P values alive/deceased \\
\hline BMI & $27.1(6.6)$ & $25.9(5.5)$ & 0.2267 \\
Age & $62.7(13.3)$ & $63.0(13.9)$ & 0.8904 \\
TAT L3/4 & $399.5(214.1)$ & $341.8(197.1)$ & 0.1014 \\
VAT L3/4 & $117.6(80.7)$ & $115.7(81.2)$ & 0.8908 \\
SAT L3/4 & $302.8(213.0)$ & $285.1(298.0)$ & 0.7163 \\
VAT/SAT & $0.47(0.5)$ & $0.56(0.3)$ & 0.1714 \\
SMI L3/4 & $43.6(8.0)$ & $41.3(12.8)$ & 0.2562 \\
IMFA & $37.6(18.7)$ & $36.2(16.7)$ & 0.6249 \\
\hline
\end{tabular}

$\mathrm{SD}=$ standard deviation, $\mathrm{TAT}=$ total adipose tissue, $\mathrm{VAT}=$ visceral adipose tissue, $\mathrm{SAT}=$ subcutaneous adipose tissue, SMI-skeletal-muscle-index, IMFA= inter-muscular-fat-area.
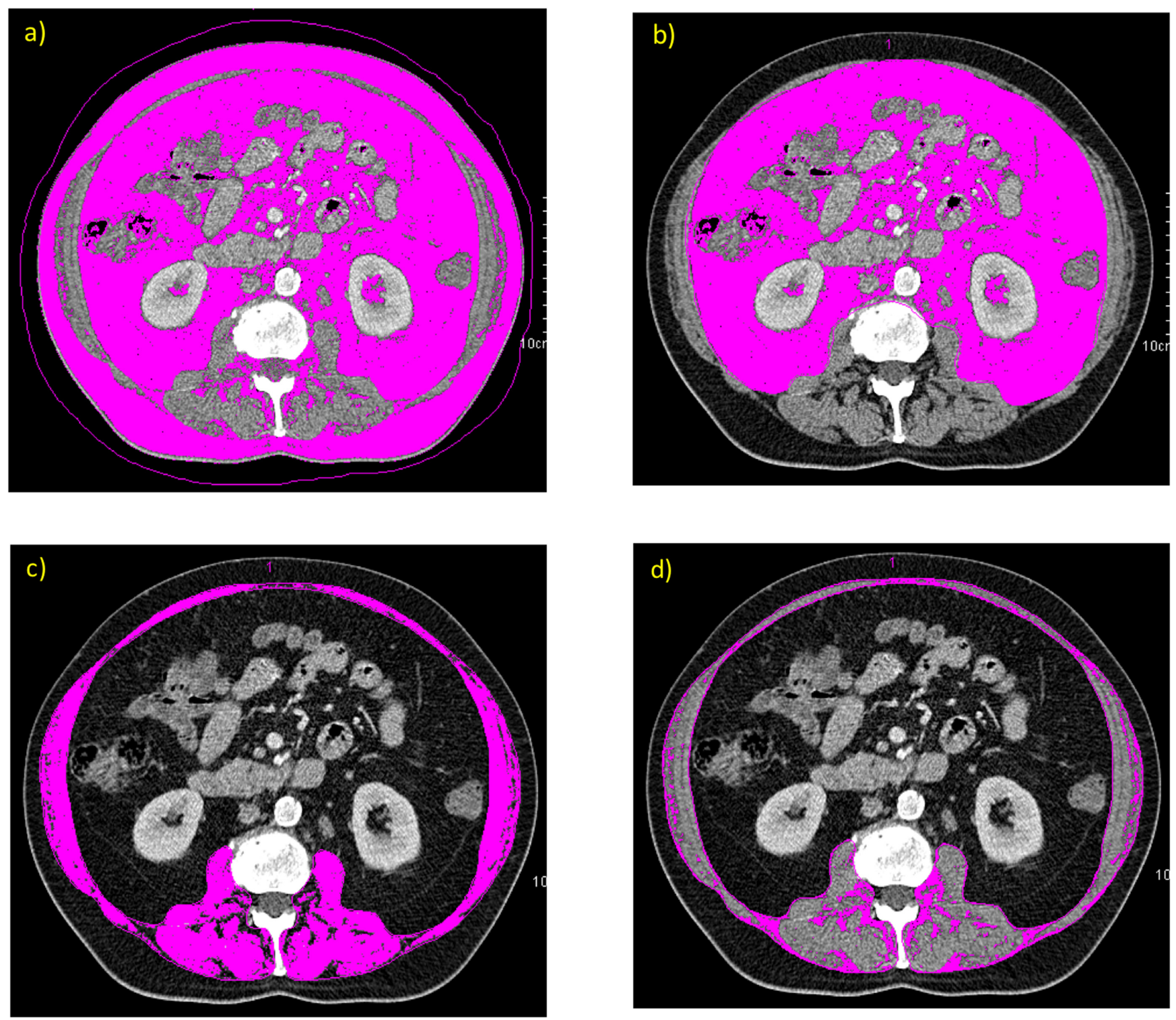

Figure 1: Example of densitometric quantification of adipose tissue area (threshold: -190 to $-30 \mathrm{HU}$ ) in a CT scan at level L3/4: ROI determining TAT (a) and VAT (b). Example of densitometric quantification of muscle area in a CT-scan at level L 3/4 with ROI determining muscle compartments with threshold: -29 to $+150 \mathrm{HU}$ (c) and IMFA with threshold: -190 to-30HU (d). 
Table 4: Univariate survival analysis of all study participants with Cox regression, $\mathbf{n}=189$

\begin{tabular}{|c|c|c|c|c|}
\hline Variable & $\begin{array}{l}\text { Probability } \\
\text { Chi-square }\end{array}$ & $\begin{array}{c}\text { Hazard } \\
\text { Ratio }\end{array}$ & $\begin{array}{l}\text { Parameter } \\
\text { Estimate }\end{array}$ & $\begin{array}{l}\text { 95\% Hazard Ratio } \\
\text { Confidence Limits }\end{array}$ \\
\hline BMI & 0.3774 & 0.977 & -0.02290 & $0.929 / 1.028$ \\
\hline Age & 0.8104 & 1.003 & 0.00263 & $0.981 / 1.024$ \\
\hline TAT L3/4 & 0.1912 & 0.999 & -0.00104 & $0.997 / 1.001$ \\
\hline VAT L3/4 & 0.9164 & 1.000 & 0.0001990 & $0.996 / 1.004$ \\
\hline SAT L3/4 & 0.7513 & 1.000 & -0.000241 & $0.998 / 1.001$ \\
\hline VAT/SAT & 0.1167 & 1.396 & 0.33384 & $0.920 / 2.119$ \\
\hline SMI L3/4 & 0.0717 & 0.975 & -0.02560 & $0.948 / 1.002$ \\
\hline IMFA & 0.9366 & 0.999 & -0.000670 & $0.983 / 1.016$ \\
\hline \multicolumn{5}{|c|}{ Subgroup cervix } \\
\hline SMI L3/4 & 0.0226 & 0.959 & -0.04158 & $0.926 / 0.994$ \\
\hline
\end{tabular}

$\mathrm{SD}=$ standard deviation, $\mathrm{TAT}=$ total adipose tissue, $\mathrm{VAT}=$ visceral adipose tissue, $\mathrm{SAT}=$ subcutaneous adipose tissue, SMI-skeletal-muscle-index, IMFA= inter-muscular-fat-area.

an exact quantification of total abdominal adipose tissue including visceral and subcutaneous adipose tissue as well as muscle tissue with an assessment of the skeletal-muscle index (SMI) including intramuscular fat content. Firstly, we investigated the total and age stratified distribution of adipose tissue and found a female specific distribution: the SAT was higher compared to the VAT. This is known from other, non-gynecological malignancies as reported in our previous studies [31]. Secondly, we investigated differences regarding body composition between the groups of surviving versus deceased patients. Here we didn't find any significant differences in adipose tissue compartments, muscle tissue or BMI. Thirdly, we conducted univariate and multivariate analyses to find possible parameters with impact on overall survival. However, no such significant parameters were found

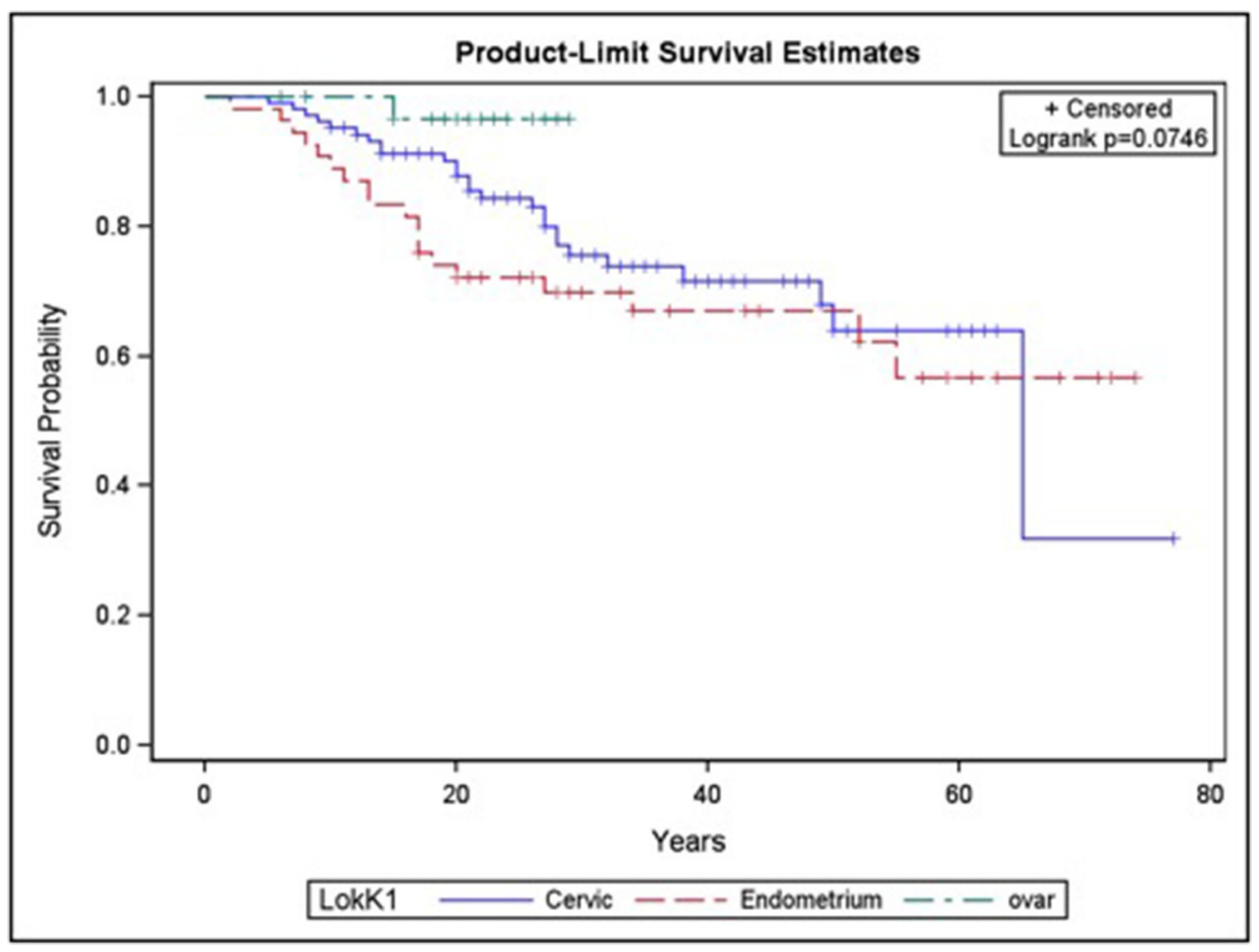

Figure 2: Kaplan-Meier analysis of patients with endometrium $(n=54)$, ovarian $(n=31)$ and cervical cancer $(n=104)$. 
regarding adipose or BMI. SMI showed a general positive trend in all cancers. This means that high amounts of muscle tissue were protective regarding risk of death. Others have shown a significant impact of SMI on survival e.g. in a cohort of lung cancer [32]. The subgroup analysis of cervical cancer goes along with the results from the former mentioned lung cancer study by Nattenmüller et al. as a significant protective impact by SMI was also found. In the subgroups of EC and OC no significant impact of body composition on survival was found. Especially for OC this can be impacted by short follow up period in this subgroup as well as the sample size.

It is known that adiposity as well as gains in body circumference measures are risk factors for cancer occurrence. For example, Aune et al. described a risk increase for EC associated with a ten centimeter increase of waist and hip circumferences as well as waist/hip ratio. Of all gynecologic tumors, EC is most strongly associated with obesity $[8,33]$. The large cohort study by Bhaskaran describes relative risks caused by adiposity for $\mathrm{CC}, \mathrm{OC}$ and EC ranging from 1.09 to 1.62 [33].

In literature, the influence of BMI on outcome in these three analyzed tumors differs, and highlights the individual character of each tumor. Regarding OC, the influence of BMI on prognosis remains questionable $[34,35]$. One explanation may be that BMI is not able to reflect the exact body composition. In patients with OC, often cachexia and/or ascites are seen at diagnosis, which also impact the BMI [34]. Also, ascites might indicate a higher FIGO state and does not take other personal factors such as age and race into account $[36,37]$. Nevertheless, a higher BMI, measured years before OC-diagnosis, might be a negative prognostic factor $[34,35]$.

$\mathrm{CC}$ and $\mathrm{EC}$ seem to be more directly impacted by $\mathrm{BMI}$ in respect to outcome. Morbidly obese CC patients have a significantly worse prognosis regarding both OS and cancer-specific survival (CSS) [38]. Data shown in literature, however, are diverse: Frumovitz et al. describe equivalent mortality risks for obese, overweight and normal weight patients [38], whereas other studies showed significantly decreased OS also in obese and overweight patients and a non-significantly decreased CSS [39].

Although an association exists between high BMI in EC patients and positive prognostic histological features such as type I histology and good differentiation, OS significantly decreases with rising BMI [23, 40]. The high obesity-associated cardiovascular mortality in ECpatients, which is 8.8 times higher compared to the general population, is noteworthy in this context [41]. Regarding CSS, a systematic review by Arem and Irving showed no negative prognostic effect of BMI, but few studies exist [40]. A significant negative correlation of CSS with age and BMI among EC patients was noted by Benedetti Pancini et al., revealing a worse CSS for women with a BMI of more than $30 \mathrm{~kg} / \mathrm{m}^{2}$ aged 65 and above [42].
Tumor-related causes for increased mortality in obese patients may include more limited options in standard diagnostics as well as in therapeutic tools such as lower radiotherapy effectiveness, limitation of chemotherapeutic doses and obesity-specific surgical complications. Also, a lack of screening in obese populations could play a role [39]. Studies examining body composition have shown that lower muscle mass is associated with surgical complications regardless of BMI [37]. Others found higher surgical complication rates in obese EC patients [43, 44]. This in turn might lead to suboptimal treatment in obese patients. Studies on obese cervical cancer patients with early stage disease showed that these populations are less likely to be operated with a radical hysterectomy compared to normal-weight patients $[39,45]$. Lower subcutaneous and muscular fat in stage III-IV OC patients were associated with a significantly longer hospital stay and decreased OS [46], which reflects sarcopenia. Accordingly, in the CC-subgroup analyses we found a protective effect of high SMI on survival, which reflects that patients without sarcopenia fare better.

Complications during and after operation delay the onset of adjuvant therapy, which is described among obese patients and known as independent negative prognostic factor [37, 47]. Reduced effect of chemotherapy and therefore worse survival is observed in obese patients, when the dose is "capped" at a certain body surface in order to avoid allegedly higher toxicity - regardless of the actual body surface [23, 35, 38, 39]. Common comorbidities of obese patients might also lead to reduced tolerability [35].

Radiation therapy in obese patients also poses special challenges $[23,38,48]$. As the distance to the tumor is larger, higher energy is needed in obese patients, which may lead to overdose in peripheral soft tissues and excess doses to organs at risk [23, 38, 48]. Furthermore, laxity of the skin can lead to inaccuracies in day-to-day setup [38].

In contrast to those previous cohort studies we assess obesity as well as cachexia in a more personalized and exact manner by measuring body composition directly, independent of the presence of ascites for example. Studies on body composition in other tumor entities showed an impact on oncologic outcomes [36]. Sarcopenia, diagnosed with CT imaging was significantly associated with inferior survival across tumor types and disease stages [36]. Particularly studies on OC showed differing results for the correlation of BMI and disease risk [49] [4, 50]. This might support our finding that fat tissue is more complex and needs further stratification for example by investigating metabolomic and immunological factors in order to create risk profiles that go beyond just BMI and general tumor entity. It also empathizes that the underlying pathomechanisms are more complex and are not fully understood. We hypothesize that there are other factors defining risk than just BMI-measured obesity. 
Prospective studies are needed to evaluate the composition of different adipose tissues and their influence on prognosis, also addressing tumor cachexia that goes along with a loss of muscle tissue and triggers metastasized disease. Biomarker studies alongside might find predictive factors for the loss of muscle tissue and changes in fat volumes. Previous investigations have shown that elevated inflammation markers, a sign of negative outcome in oncologic patients, are associated with decreased muscle mass but have no association with BMI [51]. Other studies investigating adipocyte-derived free fatty acids have shown a causative link to cancer cell proliferation and invasive properties, which might impact prognosis [52]. Such studies might lead to clinical recommendations, for example the earlier use of parenteral food to increase caloric intake and prevent the metabolomics switch. This also poses the question whether and to what extent the measured fat tissue should be set in relation to muscle tissue, though we could only detect an impact of muscle mass in CC in our cohort. The BMI cannot be principally regarded as a negative prognostic factor as "overweight" patients might for example have higher levels of protective muscle tissue ("obesity paradox") [53].

This study is subject to the following limitations: as a retrospective study, missing data could not be analyzed, such as smoking status, health status, physical exercise, nutritional habits or cause of death. The differences in fat distribution by race and age were not taken into account. Underweight patients were not excluded and might have led to bias as they also are at higher risk of death due to therapeutic complications and cachexia. As a single center study a selection bias cannot be excluded. CT-scans of different origin and with different protocols were used, however, as all CT-scans were normalized for slice-thickness and adipose tissue quantification is highly reproducible, this should have no impact on our analysis. Because of subgroups with different cancer entities, significant associations in smaller subgroups may be masked.

In conclusion, obesity is a complex disease. The underlying pathomechanisms in cancer patients need further investigation to understand its complexity with respect to cancer development and progression, therapeutic response and its impact on overall prognosis. CT-quantified fat measurements might be a useful tool to examine associations beyond BMI alone. The combination of liquid biopsy, metabolomics, radiomics and exact body composition might be a future approach for an adequate risk assessment among obese cancer patients. Larger studies addressing cancer subtypes are also needed to enhance clinical relevance of such assessments.

\section{MATERIALS AND METHODS}

\section{Study population and study protocol}

This retrospective study conducted at the Department of Gynecology and Obstetrics, University
Hospital Heidelberg was approved by the local ethic committee (S-558/2014). All female patients with a gynecological malignancy referred for a surgical treatment to the University Hospital Heidelberg were identified using the medical documentation system (SAP ECC 6.0 EhP5 SP 14 IS-H 605 SP 25) and assessed for eligibility. The inclusion was suitable if CT-scans were available prior to surgery and follow up data were accessible. This was conferred with an extract of the local tumor documentation system, that was also used for survival inquiries. Clinical data relevant for this study were extracted from the medical records. Subjects were categorized upon their tumor entity.

\section{Quantification of adipose tissue and muscle tissue via CT}

We retrieved abdominal CT-scans from the institutional picture and archiving system (PACS, GE Medical Systems, Buckinghamshire, UK). Area-based quantification of adipose tissue compartments was conducted on one representative image slice at level between vertebral-body L3/4 using a semiautomatic software tool (Syngo Volume tool, Siemens Healthcare, Munich, Berlin, Germany) [54]. By manually defining regions of interest (ROI), the total-adipose-tissue (TAT, whole circumference of abdomen) and the visceraladipose-tissue (VAT, marking the abdominal wall along the fascial plane) were quantified (volumetric measurement of selected slice, divided by slice thickness) as preformed in previous studies [31]. Measurement thresholds with a lower attenuation limit of $-190 \mathrm{HU}$ and an upper attenuation limit of -30 HU were chosen to selectively measure adipose tissue within these ROIs as previously described $[31,55]$. By subtracting VAT from TAT subcutaneous adipose tissue (SAT) was calculated. The visceral-to-subcutaneous-fat ratio was calculated as VFA/SFA.

On the identical image slice (L3/4) a ROI containing all muscles (M.erector spinae, M.psoas major, M.latissimus dorsi, M.quadratus lumborum, M.transversus abdominis, M.obliquus abdominis externus and internus abdominis and M.rectus abdominis) was manually defined (volumetric quantification of selected slice, divided by slice thickness) $[31,32]$. Muscle tissue was selected by limiting the measurements to a lower attenuation limit of -29 HU and an upper attenuation limit of $150 \mathrm{HU}$ $\left(\mathrm{MA}_{150}\right.$, Figure $\left.\mathrm{X}\right)[32,56,57]$. To measure only adipose tissue within muscle compartments (inter-muscular-fatarea, IMFA) a limit of -190 to $-30 \mathrm{HU}$ was chosen [32]. Mean muscle density in HU of each ROI was recorded (MD) and skeletal-muscle-index (SMI) was defined as $\mathrm{SMI}=$ muscle $_{150} /\left(\right.$ height $\left.^{2}\right)$ with the unit $\mathrm{cm}^{2} / \mathrm{m}^{2}[56,58]$. An exemplary image of the CT-based body composition quantification is shown in Figure 2.

According to Martin et al. we defined sarcopenia an $\mathrm{SMI}<41 \mathrm{~cm}^{2} / \mathrm{m}^{2}[56]$. 


\section{Statistical analysis}

The statistical analyses were performed using SAS 9.4 (SAS Institute Inc, Cary, NC, US). Continuous data were reported as means with standard deviations and categorical data as absolute and relative frequencies. The Spearman rank correlation coefficient was used to evaluate correlations between ordinal variables, while the t-test and the Wilcoxon U-test was used to test for differences between groups in the case of continuous data or scores. The chi-squared test was performed to evaluate differences between categorical data. Log-rank-test was used to compare survival curves and hazard-ratios were calculated to estimate risks. $\mathrm{p}<0.05$ (two-sided) was regarded as statistically significant.

\section{Author contributions}

SS, JR and JN: prepared the manuscript and had the primary responsibility for its final content. All authors critically revised the manuscript and approved its final content. JA, JN: evaluated the imaging data; TB: carried out the statistical analyses; JN, SS, JR: designed the trial. SS and JA: acquired the data.

\section{ACKNOWLEDGMENTS}

We thank Prof. Dr. Nikolaus Becker, Daniela Beister and Sophia Schäfer from the Division of Cancer Epidemiology at the German Cancer Research Center (DKFZ) for building the database and for supporting the data collection.

\section{CONFLICTS OF INTEREST}

The authors of this manuscript declare no relationships with any companies, whose products or services may be related to the subject matter of the article.

\section{FUNDING} funding.

The authors state that this work has not received any

\section{REFERENCES}

1. Afshin A, Forouzanfar MH, Reitsma MB, Sur P, Estep K, Lee A, Marczak L, Mokdad AH, Moradi-Lakeh M, Naghavi M, Salama JS, Vos T, Abate KH, et al, and The GBD 2015 Obesity Collaborators. Health Effects of Overweight and Obesity in 195 Countries over 25 Years. N Engl J Med. 2017; 377:13-27. https://doi.org/10.1056/NEJMoa1614362.

2. Berrington de Gonzalez A, Hartge P, Cerhan JR, Flint AJ, Hannan L, MacInnis RJ, Moore SC, Tobias GS, AntonCulver H, Freeman LB, Beeson WL, Clipp SL, English DR, et al. Body-mass index and mortality among 1.46 million white adults. N Engl J Med. 2010; 363:2211-19. https://doi. org/10.1056/NEJMoa1000367.

3. Grio R, Porpiglia M. Obesity: internal medicine, obstetric and gynecological problems related to overweight. Panminerva Med. 1994; 36:138-41.

4. Leitzmann MF, Koebnick C, Danforth KN, Brinton LA, Moore SC, Hollenbeck AR, Schatzkin A, Lacey JV Jr. Body mass index and risk of ovarian cancer. Cancer. 2009; 115:812-22. https://doi.org/10.1002/cncr.24086.

5. Maccio A, Madeddu C, Gramignano G, Mulas C, Floris C, Massa D, Astara G, Chessa P, Mantovani G. Correlation of body mass index and leptin with tumor size and stage of disease in hormone-dependent postmenopausal breast cancer: preliminary results and therapeutic implications. J Mol Med (Berl). 2010; 88:677-86. https://doi.org/10.1007/ s00109-010-0611-8.

6. DeMaria EJ. Bariatric surgery for morbid obesity. N Engl J Med. 2007; 356:2176-83. https://doi.org/10.1056/ NEJMct067019.

7. Modesitt SC, Hallowell PT, Slack-Davis JK, Michalek RD, Atkins KA, Kelley SL, Arapovic S, Shupnik MA, Hoehn K. Women at extreme risk for obesity-related carcinogenesis: baseline endometrial pathology and impact of bariatric surgery on weight, metabolic profiles and quality of life. Gynecol Oncol. 2015; 138:238-45. https:// doi.org/10.1016/j.ygyno.2015.05.015.

8. Renehan AG, Tyson M, Egger M, Heller RF, Zwahlen M. Body-mass index and incidence of cancer: a systematic review and meta-analysis of prospective observational studies. Lancet. 2008; 371:569-78. https://doi.org/10.1016/ S0140-6736(08)60269-X.

9. Calle EE, Rodriguez C, Walker-Thurmond K, Thun MJ. Overweight, obesity, and mortality from cancer in a prospectively studied cohort of U.S. adults. N Engl J Med. 2003; 348:1625-38. https://doi.org/10.1056/ NEJMoa021423.

10. Renehan AG, Zwahlen M, Egger M. Adiposity and cancer risk: new mechanistic insights from epidemiology. Nat Rev Cancer. 2015; 15:484-98. https://doi.org/10.1038/nrc3967.

11. Veronese N, Li Y, Manson JE, Willett WC, Fontana L, Hu FB. Combined associations of body weight and lifestyle factors with all cause and cause specific mortality in men and women: prospective cohort study. BMJ. 2016; 355: i5855. https://doi.org/10.1136/bmj.i5855.

12. Gregg EW, Shaw JE. Global health effects of overweight and obesity. N Engl J Med. 2017; 377:80-81. https://doi. org/10.1056/NEJMe1706095.

13. Iglesias DA, Westin SN, Rallapalli V, Huang M, Fellman B, Urbauer D, Frumovitz M, Ramirez PT, Soliman PT. The effect of body mass index on surgical outcomes and survival following pelvic exenteration. Gynecol Oncol. 2012; 125:336-42. https://doi.org/10.1016/j.ygyno.2012.01.010. 
14. Suidan RS, Leitao MM Jr, Zivanovic O, Gardner GJ, Long Roche KC, Sonoda Y, Levine DA, Jewell EL, Brown CL, Abu-Rustum NR, Charlson ME, Chi DS. Predictive value of the Age-Adjusted Charlson Comorbidity Index on perioperative complications and survival in patients undergoing primary debulking surgery for advanced epithelial ovarian cancer. Gynecol Oncol. 2015; 138:24651. https://doi.org/10.1016/j.ygyno.2015.05.034.

15. Grignol VP, Smith AD, Shlapak D, Zhang X, Del Campo $\mathrm{SM}$, Carson WE. Increased visceral to subcutaneous fat ratio is associated with decreased overall survival in patients with metastatic melanoma receiving antiangiogenic therapy. Surg Oncol. 2015; 24:353-58. https:// doi.org/10.1016/j.suronc.2015.09.002.

16. Guiu B, Petit JM, Bonnetain F, Ladoire S, Guiu S, Cercueil JP, Krause D, Hillon P, Borg C, Chauffert B, Ghiringhelli F. Visceral fat area is an independent predictive biomarker of outcome after first-line bevacizumab-based treatment in metastatic colorectal cancer. Gut. 2010; 59:341-47. https:// doi.org/10.1136/gut.2009.188946.

17. Ladoire S, Bonnetain F, Gauthier M, Zanetta S, Petit JM, Guiu S, Kermarrec I, Mourey E, Michel F, Krause D, Hillon P, Cormier L, Ghiringhelli F, Guiu B. Visceral fat area as a new independent predictive factor of survival in patients with metastatic renal cell carcinoma treated with antiangiogenic agents. Oncologist. 2011; 16:71-81. https:// doi.org/10.1634/theoncologist.2010-0227.

18. Mirsoian A, Murphy WJ. Obesity and cancer immunotherapy toxicity. Immunotherapy. 2015; 7:31922. https://doi.org/10.2217/imt.15.12.

19. Lauby-Secretan B, Scoccianti C, Loomis D, Grosse Y, Bianchini F, Straif $\mathrm{K}$ for the International Agency for Research on Cancer Handbook Working Group. Body Fatness and Cancer-Viewpoint of the IARC Working Group. N Engl J Med. 2016; 375:794-98. https:/doi. org/10.1056/NEJMsr1606602.

20. La Vecchia C, Franceschi S, Decarli A, Gallus G, Tognoni G. Risk factors for endometrial cancer at different ages. J Natl Cancer Inst. 1984; 73:667-71.

21. Renehan AG, Roberts DL, Dive C. Obesity and cancer: pathophysiological and biological mechanisms. Arch Physiol Biochem. 2008; 114:71-83. https://doi. org/10.1080/13813450801954303.

22. Aune D, Navarro Rosenblatt DA, Chan DS, Vingeliene S, Abar L, Vieira AR, Greenwood DC, Bandera EV, Norat T. Anthropometric factors and endometrial cancer risk: a systematic review and dose-response meta-analysis of prospective studies. Ann Oncol. 2015; 26:1635-48. https:// doi.org/10.1093/annonc/mdv142.

23. Secord AA, Hasselblad V, Von Gruenigen VE, Gehrig PA, Modesitt SC, Bae-Jump V, Havrilesky LJ. Body mass index and mortality in endometrial cancer: A systematic review and meta-analysis. Gynecol Oncol. 2016; 140:184 90. https://doi.org/10.1016/j.ygyno.2015.10.020.
24. Olsen CM, Green AC, Whiteman DC, Sadeghi S, Kolahdooz F, Webb PM. Obesity and the risk of epithelial ovarian cancer: a systematic review and meta-analysis. Eur J Cancer. 2007; 43:690-709. https://doi.org/10.1016/j. ejca.2006.11.010.

25. Ligibel JA, Cirrincione CT, Liu M, Citron M, Ingle JN, Gradishar W, Martino S, Sikov W, Michaelson R, Mardis E, Perou CM, Ellis M, Winer E, et al. Body Mass Index, PAM50 Subtype, and Outcomes in Node-Positive Breast Cancer: CALGB 9741 (Alliance). J Natl Cancer Inst. 2015; 107: djv179. https://doi.org/10.1093/jnci/djv179.

26. Tran AQ, Cohen JG, Li AJ. Impact of obesity on secondary cytoreductive surgery and overall survival in women with recurrent ovarian cancer. Gynecol Oncol. 2015; 138:26366. https://doi.org/10.1016/j.ygyno.2015.05.035.

27. Nagata N, Sakamoto K, Arai T, Niikura R, Shimbo T, Shinozaki M, Aoki T, Kishida Y, Sekine K, Tanaka S, Okubo H, Watanabe K, Sakurai T, et al. Visceral abdominal fat measured by computed tomography is associated with an increased risk of colorectal adenoma. Int J Cancer. 2014; 135:2273-81. https://doi.org/10.1002/ijc.28872.

28. Rickles AS, Iannuzzi JC, Mironov O, Deeb AP, Sharma A, Fleming FJ, Monson JR. Visceral obesity and colorectal cancer: are we missing the boat with BMI? J Gastrointest Surg. 2013; 17:133-43. https://doi.org/10.1007/ s11605-012-2045-9.

29. Doyle SL, Donohoe CL, Lysaght J, Reynolds JV. Visceral obesity, metabolic syndrome, insulin resistance and cancer. Proc Nutr Soc. 2012; 71:181-89. https://doi.org/10.1017/ S002966511100320X.

30. Xie B, Waters MJ, Schirra HJ. Investigating potential mechanisms of obesity by metabolomics. J Biomed Biotechnol. 2012; 2012:805683. https://doi. org/10.1155/2012/805683.

31. Nattenmueller J, Hoegenauer H, Boehm J, Scherer D, Paskow M, Gigic B, Schrotz-King P, Grenacher L, Ulrich C, Kauczor HU. CT-based compartmental quantification of adipose tissue versus body metrics in colorectal cancer patients. Eur Radiol. 2016; 26:4131-40. https://doi. org/10.1007/s00330-016-4231-8.

32. Nattenmuller J, Wochner R, Muley T, Steins M, Hummler $\mathrm{S}$, Teucher B, Wiskemann J, Kauczor HU, Wielputz MO, Heussel CP. Prognostic Impact of CT-Quantified Muscle and Fat Distribution before and after First-LineChemotherapy in Lung Cancer Patients. PLoS One. 2017; 12:e0169136. https://doi.org/10.1371/journal. pone. 0169136 .

33. Bhaskaran K, Douglas I, Forbes H, dos-Santos-Silva I, Leon DA, Smeeth L. Body-mass index and risk of 22 specific cancers: a population-based cohort study of 5.24 million UK adults. Lancet. 2014; 384:755-65. https://doi. org/10.1016/S0140-6736(14)60892-8.

34. Bae HS, Kim HJ, Hong JH, Lee JK, Lee NW, Song JY. Obesity and epithelial ovarian cancer survival: a 
systematic review and meta-analysis. J Ovarian Res. 2014; 7:41. https://doi.org/10.1186/1757-2215-7-41.

35. Yang HS, Yoon C, Myung SK, Park SM. Effect of obesity on survival of women with epithelial ovarian cancer: a systematic review and meta-analysis of observational studies. Int J Gynecol Cancer. 2011; 21:1525-32. https:// doi.org/10.1097/IGC.0b013e31822eb5f8.

36. Kazemi-Bajestani SM, Mazurak VC, Baracos V. Computed tomography-defined muscle and fat wasting are associated with cancer clinical outcomes. Semin Cell Dev Biol. 2016; 54:2-10. https://doi.org/10.1016/j.semcdb.2015.09.001.

37. Strulov Shachar S, Williams GR. The obesity paradox in cancer-moving beyond BMI. Cancer Epidemiol Biomarkers Prev. 2017; 26:13-16. https://doi.org/10.1158/1055-9965. EPI-16-0439.

38. Frumovitz M, Jhingran A, Soliman PT, Klopp AH, Schmeler KM, Eifel PJ. Morbid obesity as an independent risk factor for disease-specific mortality in women with cervical cancer. Obstet Gynecol. 2014; 124:1098-104. https://doi. org/10.1097/AOG.0000000000000558.

39. Clark LH, Jackson AL, Soo AE, Orrey DC, Gehrig PA, Kim $\mathrm{KH}$. Extremes in body mass index affect overall survival in women with cervical cancer. Gynecol Oncol. 2016; 141:497-500. https://doi.org/10.1016/j.ygyno.2016.03.035.

40. Arem H, Irwin ML. Obesity and endometrial cancer survival: a systematic review. Int J Obes. 2013; 37:634 39. https://doi.org/10.1038/ijo.2012.94.

41. Felix AS, Bower JK, Pfeiffer RM, Raman SV, Cohn DE, Sherman ME. High cardiovascular disease mortality after endometrial cancer diagnosis: results from the Surveillance, Epidemiology, and End Results (SEER) Database. Int J Cancer. 2017; 140:555-64. https://doi.org/10.1002/ ijc.30470.

42. Benedetti Panici P, Basile S, Salerno MG, Di Donato V, Marchetti C, Perniola G, Palagiano A, Perutelli A, Maneschi F, Lissoni AA, Signorelli M, Scambia G, Tateo S, et al. Secondary analyses from a randomized clinical trial: age as the key prognostic factor in endometrial carcinoma. Am J Obstet Gynecol. 2014; 210:363.e1-e10. https://doi. org/10.1016/j.ajog.2013.12.025.

43. Uccella S, Bonzini M, Palomba S, Fanfani F, Ceccaroni M, Seracchioli R, Vizza E, Ferrero A, Roviglione G, Casadio P, Corrado G, Scambia G, Ghezzi F. Impact of obesity on surgical treatment for endometrial cancer: a multicenter study comparing laparoscopy vs open surgery, with propensity-matched analysis. J Minim Invasive Gynecol. 2016; 23:53-61. https://doi.org/10.1016/j.jmig.2015.08.007.

44. Orekoya O, Samson ME, Trivedi T, Vyas S, Steck SE. The impact of obesity on surgical outcome in endometrial cancer patients: a systematic review. J Gynecol Surg. 2016; 32:149-57. https://doi.org/10.1089/gyn.2015.0114.

45. Frumovitz M, Sun CC, Jhingran A, Schmeler KM, Dos Reis R, Milam MR, Soliman PT, Taylor K, Ramirez PT. Radical hysterectomy in obese and morbidly obese women with cervical cancer. Obstet Gynecol. 2008; 112:899905. https://doi.org/10.1097/AOG.0b013e3181863280.

46. Torres ML, Hartmann LC, Cliby WA, Kalli KR, Young PM, Weaver AL, Langstraat CL, Jatoi A, Kumar S, Mariani A. Nutritional status, CT body composition measures and survival in ovarian cancer. Gynecol Oncol. 2013; 129:54853. https://doi.org/10.1016/j.ygyno.2013.03.003.

47. Joseph N, Clark RM, Dizon DS, Lee MS, Goodman A, Boruta D Jr, Schorge JO, Del Carmen MG, Growdon WB. Delay in chemotherapy administration impacts survival in elderly patients with epithelial ovarian cancer. Gynecol Oncol. 2015; 137:401-05. https://doi.org/10.1016/j. ygyno.2015.03.052.

48. Yavas G, Yavas C, Kerimoglu OS, Celik C. The impact of body mass index on radiotherapy technique in patients with early-stage endometrial cancer: a single-center dosimetric study. Int J Gynecol Cancer. 2014; 24:1607-15. https://doi. org/10.1097/IGC.0000000000000298.

49. Collaborative Group on Epidemiological Studies of Ovarian Cancer. Ovarian cancer and body size: individual participant meta-analysis including 25,157 women with ovarian cancer from 47 epidemiological studies. PLoS Med. 2012; 9:e1001200. https://doi.org/10.1371/journal.pmed.1001200.

50. Canchola AJ, Chang ET, Bernstein L, Largent JA, Reynolds P, Deapen D, Henderson KD, Ursin G, Horn-Ross PL. Body size and the risk of ovarian cancer by hormone therapy use in the California Teachers Study cohort. Cancer Causes Control. 2010; 21:2241-48. https://doi.org/10.1007/ s10552-010-9647-x.

51. Malietzis G, Johns N, Al-Hassi HO, Knight SC, Kennedy RH, Fearon KC, Aziz O, Jenkins JT. Low muscularity and myosteatosis is related to the host systemic inflammatory response in patients undergoing surgery for colorectal cancer. Ann Surg. 2016; 263:320-25.https://doi. org/10.1097/SLA.0000000000001113.

52. Suarez-Carmona M, Heinzelmann A, Valous NA, Hampel M, Berthel A, Schott S, Zörnig I, Jäger D, Halama N. Abstract A102: The fat in ovarian cancer: immunedependent tumor-promoting effects. Cancer Immunology Research. 2016; 4:A102. https://doi.org/10.1158/23266066.imm2016-a102.

53. Caan BJ, Kroenke CH. Next Steps in Understanding the Obesity Paradox in Cancer. Cancer Epidemiol Biomarkers Prev. 2017; 26:12. https://doi.org/10.1158/1055-9965. EPI-16-0764.

54. Irlbeck T, Massaro JM, Bamberg F, O'Donnell CJ, Hoffmann U, Fox CS. Association between single-slice measurements of visceral and abdominal subcutaneous adipose tissue with volumetric measurements: the Framingham Heart Study. Int J Obes. 2010; 34:78187. https://doi.org/10.1038/ijo.2009.279.

55. Yoshizumi T, Nakamura T, Yamane M, Islam AH, Menju M, Yamasaki K, Arai T, Kotani K, Funahashi T, Yamashita S, Matsuzawa Y. Abdominal fat: standardized technique for 
measurement at CT. Radiology. 1999; 211:283-86. https:// doi.org/10.1148/radiology.211.1.r99ap15283.

56. Martin L, Birdsell L, Macdonald N, Reiman T, Clandinin MT, McCargar LJ, Murphy R, Ghosh S, Sawyer MB, Baracos VE. Cancer cachexia in the age of obesity: skeletal muscle depletion is a powerful prognostic factor, independent of body mass index. J Clin Oncol. 2013; 31:1539-47. https://doi.org/10.1200/JCO.2012.45.2722.

57. Mitsiopoulos N, Baumgartner RN, Heymsfield SB, Lyons W, Gallagher D, Ross R. Cadaver validation of skeletal muscle measurement by magnetic resonance imaging and computerized tomography. J Appl Physiol (1985). 1998; $85: 115-22$.

58. Prado CM, Lieffers JR, McCargar LJ, Reiman T, Sawyer MB, Martin L, Baracos VE. Prevalence and clinical implications of sarcopenic obesity in patients with solid tumours of the respiratory and gastrointestinal tracts: a population-based study. Lancet Oncol. 2008; 9:62935. https://doi.org/10.1016/S1470-2045(08)70153-0. 